\title{
Understanding wildfires in mainland Spain. A comprehensive analysis of fire regime features in a climate-human context
}

\author{
Adrián Jiménez-Ruano*, Marcos Rodrigues Mimbrero, Juan de la Riva Fernández \\ GEOFOREST Group, IUCA, Department of Geography and Land Management, University of Zaragoza, Pedro Cerbuna 12, 50009, Zaragoza, Spain
}

\section{A R T ICLE INFO}

\section{Keywords:}

Fire regime features

Human pressure

Climate

Large fire

Wildfire

MGPCA

GAM

\begin{abstract}
A B S T R A C T
Understanding fire regime is a crucial step towards better knowledge of the wildfire phenomenon. However, the concept itself, in spite of its widespread use, still lacks a clear, widely accepted definition and there is no general agreement on which features define it best. In this paper we provide an in-depth characterization and description of fire regimes in three regions - Northwest, Hinterland and Mediterranean - comprising the whole of mainland Spain, to identify their key features. Data on number of fires, burned area, fire season and cause are retrieved from historical fire records for the period 1974-2010. Specifically, fire frequency, burned area, number of natural/human-caused fires, burned area from natural/human-caused fires, number of large fires ( $\geq 500$ ha), and burned area from large fires were examined for each region and fire season. We used a multi-group Principal Components Analysis approach to determine the importance of each fire regime feature. Next, climate and socioeconomic variables were explored using Multidimensional Scatterplots and Generalized Additive Models to find the extent to which fire regimes are controlled by either environmental, human, or both factors. Results revealed differences among regions and seasons in terms of the characteristics of their respective fire regimes. However, several common features have been identified as key components of fire regimes, regardless of region or fire season: fire frequency, number of large fires, and burned area from natural fires. In addition, results confirm that fire regime in the Northwest area mainly depends on human activity, especially during winter, in contrast to the Mediterranean region.
\end{abstract}

\section{Introduction}

Wildfires are one of the major environmental disturbances worldwide, playing an important role in determining the structure and functioning of many ecosystems (Archibald, Lehmann, Gómez-Dans, \& Bradstock, 2013; E. Chuvieco, 2009b; Ganteaume et al., 2013; Pausas \& Fernández-Muñoz, 2012). Understanding the complex interactions of factors involved in wildfire activity still remains an unbeaten challenge, which usually involves dealing with complex interactions among numerous variables (Krawchuk, Moritz, Parisien, Van Dorn, \& Hayhoe, 2009). In this regard, the analysis of fire regime is a crucial step towards a better comprehension of wildfires. This is especially relevant in the case of Spain, one of the most fire-affected areas within the European Mediterranean region in terms of annual cumulative burned forests (Darques, 2016).

\footnotetext{
* Corresponding author.

Email address: jimenez@unizar.es (A. Jiménez-Ruano)
}

Fire regime is usually defined as the average conditions of fire that are persistent and consistent within a particular area and over a given period (Chuvieco, 2009a, 2009b; Krebs, Pezzatti, Mazzoleni, Talbot, \& Conedera, 2010). However, there is no agreement on how fire regime should be characterized, hence the term itself still lacks a clear and well-known definition (Krebs et al., 2010), although there is a list of potential variables describing fire regime commonly accepted (Pyne, Andrews, \& Laven, 1996). Among the great variety of fire regime characteristics that are generally described, we found those such as frequency, seasonality, size, type, severity or intensity (Whitman et al., 2015). It is widely thought that fire regime components have been and still are - highly variable across time and space (M. V. Moreno, Conedera, Chuvieco, \& Pezzatti, 2014). Several studies have demonstrated that global fire regime has moved from being essentially controlled by climate factors to become more dependent on human activity (Chuvieco, 2009a, 2009b; Pechony \& Shindell, 2010), thus evolving from natural to human fire regime. On a regional scale, and particu- 
larly in the case of Spain, climate still influences fire regimes. However, human impact has steadily gained importance over time (M. V. Moreno et al., 2014). In this respect, human influence on wildfire usually has a double-edge (Syphard et al., 2007). Fire suppression helps reduce the impact of fire activity (Chuvieco, 2009a, 2009b), but simultaneously, human pressure on wildlands is nowadays a major source of ignition (Wang \& Anderson, 2010).

There are many factors involved when a fire regime characterization is approached (Murphy, Williamson, \& Bowman, 2011). Despite considerable research being applied to distinguishing attributes belonging to different fire regimes or fire regions, it remains unclear which features should be included, and further research is still needed (Archibald et al., 2013). In this regard, an approach based on inter-regional and/or inter-seasonal comparison, such as the one we propose, might be particularly suitable. Due to the huge variability of fire activity, the best features to characterize fire regimes should be those that best differentiate regions and/or seasons. A first step toward capturing the main contrasts between fire metrics is to divide the whole period of study into two seasons. Even though fire seasonality has been little studied until now, it has proven useful in analysing the influence of human activities on fire regime (Le Page, Oom, Silva, Jönsson, \& Pereira, 2010). Several authors have used different seasonal metrics as the median day of the fire season (Whitman et al., 2015), or the length of the fire season (Chuvieco, Giglio, \& Justice, 2008) or to distinguish between two seasons inside a year (vegetative and non-vegetative) (M. V. Moreno et al., 2014).

In this paper we characterize and describe in detail fire regimes in three regions - Northwest (NW), Hinterland (HL) and Mediterranean (MED) - comprising the whole of mainland Spain, to identify their key features. We explore several fire regime features under the premise that there are different fire regimes across the Spanish territory, paying special attention to seasonality, cause and the impact of large fires ( $>500$ ha; San-Miguel-Ayanz, Moreno, \& Camia, 2013). The assessment is developed from historical fire records for the period 1974-2010 from the General Statistics Forest Fires database (EGIF). Our first goal is to improve understanding of the spatial-seasonal patterns of fire regime features and analyse their influence on the fire regime itself. A second objective is to determine the extent to which fire regimes are linked to human and/or climate factors. To achieve these goals, we examined fire regimes from a quantitative and qualitative approach. The quantitative approach is based in a multi-group Principal Components Analysis which allows the most representative fire regime features to be identified and selected. In the latter, we combined the selected fire metrics with climate and human variables, and plotted their relationships using multidimensional scatterplots (MDS), then looked for patterns and relationships among these. MDS's outputs are complemented with Generalized Additive Models in order to better describe the potential relationships.

\section{Materials}

\subsection{Study area}

The study area encompasses the whole of mainland Spain (excluding Balearic and Canary archipelagos and also the autonomous cities of Ceuta and Melilla) and covers a total surface area of $498,000 \mathrm{~km}^{2}$. From a biogeographic point of view, mainland Spain is dominated by two different bioregions, Eurosiberian and Mediterranean. On the one hand, the Eurosiberian region covers the northern side of the country, including Galicia, the Cantabrian cornice and the Pyrenees and is characterized by an Oceanic climate, dominated by deciduous forest; while the Mediterranean region extends all over the remaining territory. This region is characterized by a Mediterranean climate, and is thus signifi- cantly drier and warmer than the Eurosiberian region. These conditions favour complex mosaics of plant communities of evergreen, deciduous and/or mixed forests, scrublands or natural grasslands.

Temperatures (Fig. A2, Appendix 1) vary from annual milder values in the NW provinces of the Eurosiberian region, dominated by an Oceanic climate; to warmer temperatures in the MED region, characterized by high annual thermal amplitude in the inner region and milder conditions towards the coast. The rainiest areas (Fig. A2, Appendix 1) are the Cantabrian cornice, and the highest mountain ranges as Pyrenees (Eurosiberian region) and the western Central System (inner Mediterranean region), with average values over $1000 \mathrm{~mm}$ per year and maximum during winter. On the other hand, the driest areas are located in the southeast and the Ebro Valley (inner Mediterranean region) and the province of Almeria (Mediterranean coast). Precipitation in the Mediterranean region is irregularly distributed both in time and space, with autumn-spring maximums. Human activity also changes its footprint across the territory. According to Corine Land Cover 2006, in the NW area approximately $68 \%$ of the region is covered by forests, shrubs or grassland. This land cover has been traditionally shaped by seasonal grazing at the end of the winter. In the HL region, there has been a progressive abandonment of agricultural activity (crops and pastures) which translates to around $54 \%$ of its territory being covered by wildland. Meanwhile, the Mediterranean region, the most populated area, is characterized by an extended wildland-urban interface, due to widespread urban development during the last few decades (M. V. Moreno et al., 2014).

Due to this variety of landscapes, climate and socioeconomic conditions, three different regions - NW, HL and MED - were used (Fig. 1), following the criteria from the Spanish Department of Defense Against Forest Fires (ADCIF). These regions outline homogeneous areas in terms of fire activity and seasonal averages, so that they are expected to have self-defining fire regimes (M. V. Moreno et al., 2014). The NW region includes the Autonomous Communities of Galicia, Asturias, Cantabria and the Basque Country, also the provinces of León and Zamora. This region is located within the Eurosiberian region, excluding the Pyrenees areas. Woodlands cover around $41 \%$ of this region which is characterized by long history of agricultural burning to maintain pastures and grasslands (M. V. Moreno et al., 2014). The HL region includes all of the Autonomous Communities without coastline, except for the provinces of León and Zamora (included in the NW re-

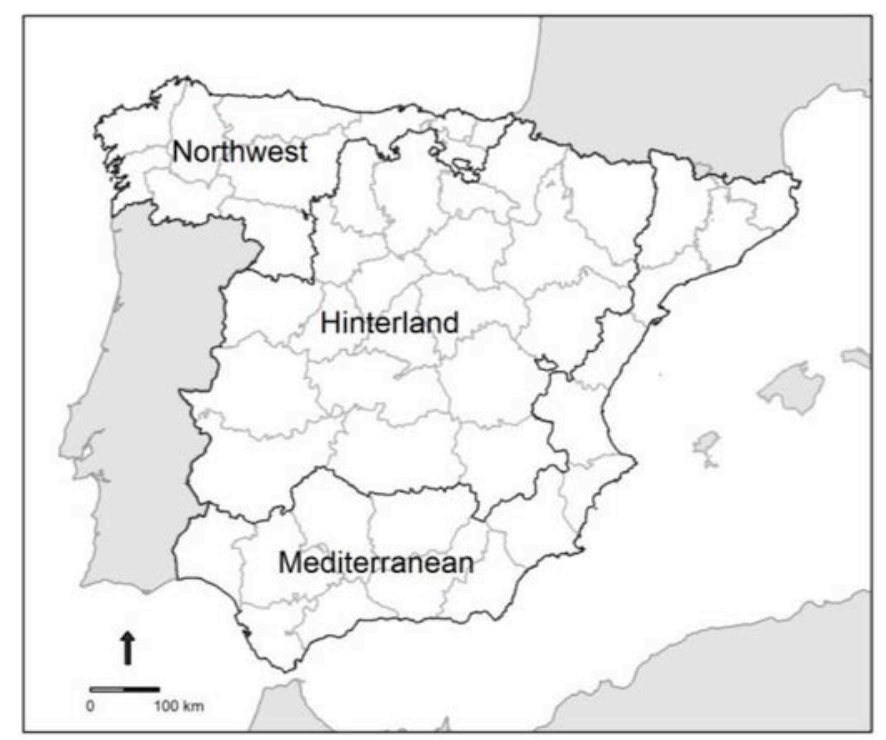

Fig. 1. Spatial distribution of the three regions and provincial division in mainland Spain. 
gion). This region, located in the Mediterranean biogeographical region, has the greatest woodland surface proportion of the whole country (approximately 61\%) mostly due to abandonment of agricultural activities and lands (M. V. Moreno et al., 2014). Finally, the MED region (also in the Mediterranean biogeographical region) includes all the Autonomous Communities along the Mediterranean coast. It has the lower woodland proportion (roughly 22\%) because of the high degree of urbanisation and tourism development.

\subsection{Fire data}

Fire data were retrieved from the General Wildfires Statistics (EGIF) database, one of the oldest 'complete' fire databases in Europe (M. V. Moreno, Malamud, \& Chuvieco, 2011; Vélez, 2001). Specifically, fire records for 1974-2010 were selected and spatialized according to the $10 \times 10 \mathrm{~km}$ UTM reference grid (referred to as fire grid) used by firefighting crews for approximate location of fire ignition points. Selected baseline information refers to sections $0,1,2,4,5$ and 9 of the Spanish Forests Fire Reports (PIF) compiled in the EGIF database. Next, fire count data, total burned area size, ignition triggering date and fire cause were retrieved for each fire event, and later separated by season and region. Note that only information about fires $\geq 1$ ha was used because small fires ( $\leq 1$ ha) were not fully compiled until 1988. The temporal time span was established according to several factors. The starting year was set as 1974, since it was the first year to use the $10 \times 10 \mathrm{~km}$ grid. Prior to that time, fire data were only recorded at province level, so grid information was not available. The ending year was selected on the basis of the availability of climate data from the MOTEDAS and MOPREDAS datasets (described below).

As stated before, regions were outlined following ADCIF specifications. In turn, two fire seasons were defined according to Moreno et al. (2014). Thus annual data were split into a spring-summer season (S), from April to September; and an autumn-winter season (W) from October to March. From all available fire data information, several fire regime features were then constructed for each region, fire season and grid cell: (i) fire frequency (F), calculated as the total number of fires; (ii) burned area size (B), as the total fire affected area; (iii) number of large fires (N500), as the total number of fires above 500 ha burned; (iv) burned area from large fires (B500), as the total affected area from fires above $500 \mathrm{ha}$; (v) number of natural fires, as the total number of fires with natural cause (NL); and (vi) burned area from natural fires, as the total burned area from fires with a natural cause (BL). Table 1 shows a statistical summary of the proposed features as well as some additional information regarding fire events with an anthropogenic source $(\mathrm{NH} / \mathrm{BH})$.

\subsection{Climate data}

Climate data were extracted from MOTEDAS (Monthly Temperature Dataset of Spain) and MOPREDAS (Monthly Precipitation Dataset of Spain) datasets. These datasets provide monthly climate information at a spatial resolution of $10 \times 10 \mathrm{~km}$, constructed from actual measurements from the Spanish Meteorological Network in the period 1951-2010 (Jose Carlos González-Hidalgo, Brunetti, \& de Luis, 2011; José Carlos González-Hidalgo, Peña-Angulo, Brunetti, \& Cortesi, 2015). MOTEDAS and MOPREDAS stand out as one of the most accurate databases in the context of climate data for mainland Spain. Their development was based on the reconstruction of meteorological data time series from each weather station in the region. In this paper, monthly data on annual average maximum temperature (T) and total precipitation (P) in the period 1974-2010 were extracted and adapted to the fire grid using a nearest neighbour procedure. Both maximum temperature and precipitation were later reclassified into 10 homogeneous (equal interval) categories (see Table A1 from Appendix 2), used to construct climate codes for the multidimensional scatterplots.

\subsection{Land use, population and Human Pressure Index}

Land use data were retrieved from Corine Land Cover 1990 (CLC), since it is centred on the temporal span. CLC information was used to outline the Wildland-Agricultural Interface (WAI) and the Wildland-Urban Interface (WUI), two variables strongly related to anthropogenic ignitions (Leone, Lovreglio, Martín, Martínez, \& Vilar, 2009; Martínez, Chuvieco, \& Martín, 2004; Rodrigues, de la Riva, \& Fotheringham, 2014). The first represents the length of the boundary between agricultural and wildland areas, and the second, the length between populated and wildland areas. Both WAI and WUI were calculated at fire grid level (Marcos Rodrigues, Jiménez, \& de la Riva, 2016). On the other hand, the Demographic Potential, which is an aggregate index for the ultimate future potential of the population, was retrieved from

Table 1

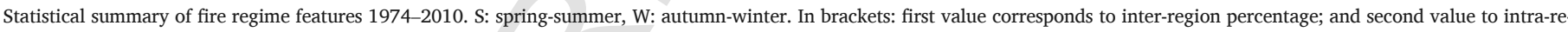

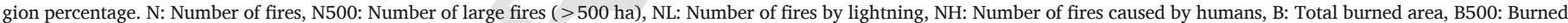
area of large fires ( $>500 \mathrm{ha}$ ), BL: Burned area of fires by lightning, BH: Burned area of fires caused by humans. Burned area data expressed in km².

\begin{tabular}{|c|c|c|c|c|c|c|c|c|c|}
\hline Region & Season & $\mathrm{N}$ & N500 & N L & $\mathrm{NH}$ & B & B500 & BL & $\mathrm{BH}$ \\
\hline \multirow[t]{6}{*}{ NW } & $S$ & 98,039 & 513 & 1385 & 66,862 & 21,557 & 4778 & 472 & 14,212 \\
\hline & & $(40.8)$ & $(30.2)$ & (26.8) & $(40.8)$ & $(34.6)$ & (20) (82.2) & (12) (98.5) & $(34.7)$ \\
\hline & & (61.7) & (81.9) & (96.4) & (59.1) & (71.5) & & & (68.5) \\
\hline & W & 60,614 & 113 & 52 & 4633 & 8586 & 1.035 & 7 & 6531 \\
\hline & & $(25.3)$ & $(6.6)(18)$ & (1) (3.6) & (28.3) & (13.8) & $(4.3)$ & $(0.2)(1.5)$ & (15.9) \\
\hline & & $(38.2)$ & & & $(40.9)$ & (28.5) & (17.8) & & (31.5) \\
\hline \multirow[t]{6}{*}{ HL } & $S$ & 33,073 & 470 & 2492 & 19,289 & 12,958 & 6572 & 1747 & 7477 \\
\hline & & (13.8) & (27.6) & $(48.2)$ & $(11.8)(68)$ & $(20.8)$ & (27.6) & (44.4) & $(18.2)(87)$ \\
\hline & & $(73.2)$ & (96.7) & (99.1) & & (89.6) & (97.8) & (99.9) & \\
\hline & W & 12,114 & 16 & 23 & 9073 & 1498 & 148 & 2 & 1112 \\
\hline & & $(5.05)$ & $(0.9)(3.3)$ & $(0.4)(0.9)$ & $(5.5)(32)$ & $(2.4)$ & $(0.6)(2.2)$ & (0) $(0.1)$ & $(2.7)$ \\
\hline & & $(26.8)$ & & & & (10.4) & & & (12.95) \\
\hline \multirow[t]{6}{*}{ MED } & $S$ & 28,289 & 513 & 1183 & 17,273 & 15,466 & 10,152 & 1686 & 10,158 \\
\hline & & (11.8) & $(30.2)$ & (22.9) & $(10.5)$ & $(24.8)$ & $(42.6)$ & (42.9) & $(24.8)$ \\
\hline & & $(78.7)$ & (87.2) & (97.4) & (77.4) & $(87.5)$ & (89.7) & (98.9) & $(87.1)$ \\
\hline & W & 7635 & 75 & 32 & 5032 & 221 & 1165 & 18 & 1508 \\
\hline & & $(3.2)(21.2)$ & $(4.4)$ & $(0.6)(2.6)$ & (3.1) (22.6) & (3.5) & (4.9) & $(0.5)$ & $(3.7)$ \\
\hline & & & (12.8) & & & (12.5) & (10.3) & (1.06) & (12.9) \\
\hline Total & & 239.764 & 1700 & 5.167 & 163.859 & 62.275 & 23.85 & 3.932 & 40.998 \\
\hline
\end{tabular}


(Calvo \& Pueyo, 2008) for 1991 at a spatial resolution of $5 \times 5 \mathrm{~km}$, later rescaled to the fire grid as the average value inside each cell. WAI, WUI and DP were normalized to a $0-1$ interval and then aggregated to develop a Human Pressure Index (HPI, Fig. 2), representing the overall pressure of human activities likely to result in fire ignition.

\section{Methods}

As mentioned before, our methodology was based on quantitative and qualitative approaches. In the first case, we used multi-group Principal Component Analysis (MGPCA) to identity key fire regime features and then investigated their relation to climate and human activity, allowing us to describe and analyse fire regimes. This methodological approach is based on the one described in Whitman et al. (2015). However, instead of putting the focus on applying PCA to aggregate climate information and then exploring their relationships with fire data, we used MGPCA combined with a Varimax Rotation (VR) procedure to identify key fire regime features and then explore their association with raw climate and socioeconomic information. Finally, relationships among fire regime features, climate and human pressure were visually explored from multidimensional scatterplots representing the qualitative approach. Additionally, MDS were complemented by a regression analysis using Generalized Additive Models (GAM) to provide deeper insights into the potential relationships among variables and features, as well as determine their statistical significance. All analyses, plots and maps were developed using the $\mathrm{R}$ statistical software ( $\mathrm{R}$ Core Team, 2016).

\subsection{Multi-group Principal Component Analysis and Varimax rotation}

With the objective of identifying the most representative fire regime features from each region and season a PCA was carried out. PCA is a classic statistical technique that has been widely used in many research fields, and wildfire modelling is no exception. However, most of the examples of PCA applied to fire science are concerned with synthesising or reducing the amount of information for regression purposes (Francos, Pereira, Alcañiz, Mataix-Solera, \& Úbeda, 2016; Fréjaville \& Curt, 2015; Marcoux et al., 2015; Xu et al., 2006). It is even less common to apply PCA to fire regime feature analysis, even though some examples can be found in Drobyshev, Niklasson, and Linderholm (2012) and Quazi and Ticktin (2016). PCA estimates the common factors which explain the variance of the input parameters. Initially vari- ables must be standardized so that each one has mean zero and unit variance, regardless of its scale. This ensures that all variables have the same weight in the analysis (Mardia, Kent, \& Bibby, 1979).

Specifically, we used a multi-group PCA (MGPCA) procedure, which is an evolution of classic PCA (Krzanowski, 1984). MGPCA can be considered an evolution of common principal components analysis (CPCA) of multi-group datasets components analysis proposed by (Flury, 1984). CPCA is defined as a generalization of PCA to the case of multi-group setting. This consists in considering the variance-covariance matrices associated to the groups and seeking common orthogonal vectors of loadings associated with the components in the groups. However, the determination of the common vectors of loadings which is based on maximum likelihood estimation leads to a complex algorithm which is time consuming and whose convergence is not granted. MGPCA is simpler and more straightforward than CPCA (Eslami, Qannari, Kohler, \& Bougeard, 2013b). MGPCA allows dealing with the variance-covariance between different groups (in our case regions and seasons). Hence, it is more suitable for group comparison (Eslami, Qannari, Kohler, \& Bougeard, 2013a, 2013b) than ordinary PCA. We applied MGPCA splitting fire data into 6 different groups, one per region (NW, HL and MED) and season (summer and winter).

The Kaiser Criterion (Kaiser, 1960) was applied to MGPCA outputs, thus retaining only those PCs with eigenvalues greater than 1 . Following this, a VR procedure was applied to determine the correlation between input variables (fire regime features) and PCs. VR consists of a PCA coordinates transformation which maximizes the sum of the variance, obtaining higher or near to zero coefficients, thus with fewer intermediate values. Consequently, the interpretation of PCA results becomes easier (Horst, 1965; Kaiser, 1958). For each PC we selected the fire regime features with a coefficient furthest from 0 , identifying them as the most representative. We considered that these features contributed the most to the behaviour of fire activity across time (season) and space (region) and thus were key parameters in the definition of fire regimes.

\subsection{Multidimensional scatterplots}

Once the key fire regime features were selected, we examined the relationships between climate variables and fire features using multidimensional scatterplots (MDS). The construction process is as follows: (i) each grid cell in the study area was coded according to its respective combination of reclassified (from 1 to 10, see Table A1 in Appendix 2) temperature and precipitation (henceforth referred to as climate

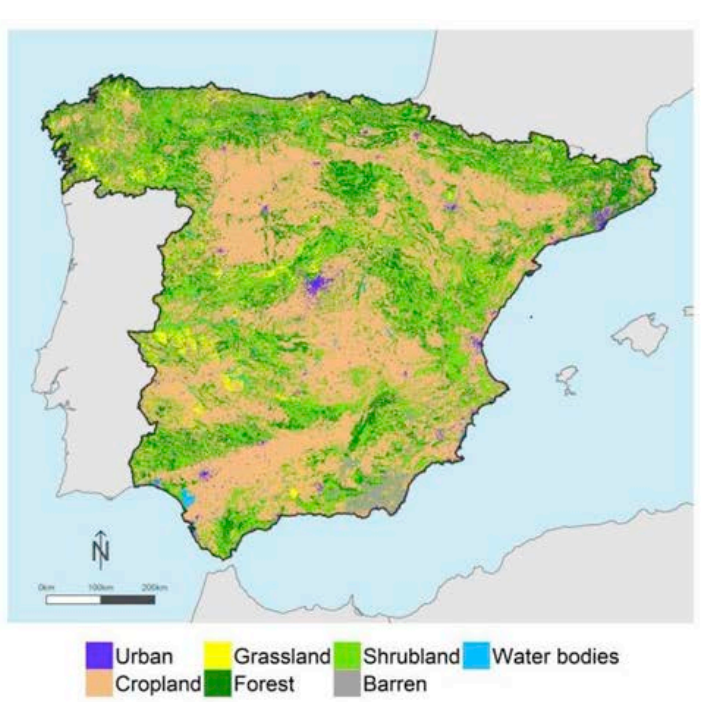

Fig. 2. Human Pressure Index (left) and generalized land cover from CLC 2006 (right). 
code); (ii) cells were then grouped on the basis of their respective climate code; (iii) fire regime features and HPI were aggregated as the sum and average value respectively; (iv) multidimensional scatterplots were then constructed. We created a two-dimensional climate space on the basis of climate codes for each region and season. On each plane, two additional variables were then plotted. $\mathrm{N}$ is always represented using proportional circles. Next, a fire regime feature was plotted on the $\mathrm{N}$ circles using different colour schemes. This led to multidimensional scatterplots, each one representing four variables (dimensions) in a single plot. Furthermore, in order to explore the relationship between human pressure, fire occurrence and climate, additional MDS were constructed representing HPI instead of fire feature. HPI was, therefore, only compared to climate and fire frequency as it mostly related to fire occurrence.

This kind of analysis has proved its potential in identifying relations amongst vegetation, climate and fire in Whitman et al. (2015). However, in our case we did not include a climate space. Instead, two climate gradients (temperature and precipitation) were used. Our goal was to determine the extent to which fire regimes are controlled by either environmental, human or both factors.

\subsection{Generalized Additive Models}

Generalized Additive Models (GAM) are Generalized Linear Models (GLM) in which the usual linear relationships between the response and predictor variables are replaced by non-linear 'smooths' (Hastie \& Tibshirani, 1986; Jones \& Almond, 1992). With the purpose of unravelling potential cause-and-effect relationships between fire features and climatic/human variables, we calibrated several GAM regressions for each MDS 'scenario'.

Same as GLM, GAM allows using probability distributions other than Gaussian. In this sense, we employed Negative Binomial to model number of fires $(\mathrm{N})$ and $\log$ linear distribution in burned area variables (B500, BL). NB is found particularly suitable to deal with zero-inflated response variables as is the case of $\mathrm{N}$ (Boadi, Harvey, \& Gyeke-dako, 2015). On the other hand, we have applied log linear family in burned area fire features (Hernandez, Keribin, Drobinski, \& Turquety, 2015). Model selection, is based on the reduction of Generalized cross validation (GCV, Craven \& Wahba, 1978; Golub, Heath, \& Wahba, 1979). GVC determines the optimal amount of smoothing and estimates the mean squared prediction error over all datasets where a single observation is omitted from the model fitting and then predicted Deviance explained (analogous to variance in a linear regression) and partial effects in the predictors were also calculated. All analyses were conducted using the R package mgcv, version 1.8-9.

\section{Results}

\subsection{Fire regime key features}

MGPCA enables the comparison of fire regions as well as determining the most relevant fire regime features. Regardless of the region or season of analysis, 3 PCs were always selected according to the Kaiser Criterion. Therefore, PCA results are only presented and analysed for the 3 first PCs (PC1, PC2 and PC3). Hence, VR was only calculated for those PCs.

According to MGPCA eigenvectors (Table 2), most of the total variance $(61 \%)$ in fire activity in the NW region during summer is associated with large fires, both in terms of number and the affected area $(\mathrm{N} 500, \mathrm{~B} 500=0.50) . \mathrm{N}$ appears on a secondary plane located in PC2 and associated with human fires (0.69). This behaviour is reversed during winter, when $\mathrm{N}$ and $\mathrm{NH}$ are promoted to $\mathrm{PC} 1$ and N500-B500 moved to PC2. In the HL region large fires seem to be playing an important role in both summer and winter, being in both cases located in PC1, although winter shows a strong link between B500 and BH. Finally, in the MED region, PC1 in summer correlates more with $\mathrm{NH}$ and $\mathrm{N}(0.51$ and 0.5 respectively). During winter, B500 displaces $\mathrm{N}$ and NH towards PC2 being associated to $\mathrm{BH}(0.46)$. Whatever the region or season, the impact of natural fires is always in PC3. In this regard, there is usually a higher correlation between burned area rather than fire counts.

Features selected on the basis of the MGPCA-VR procedure are mostly the same across regions and seasons $-\mathrm{N}$, B500 and BL- although there are differences in terms of the PC which each feature is associated with. As stated before, we consider these features to contribute the most to the behaviour of fire activity across time (season) and space (region) and thus to be key parameters in the definition of fire regimes.

\subsection{Climate-human-fire relationships}

Figs. 3-5 display MDS for N500, BL and N, respectively, whereas Table 3 and appendix S3 summarize the main outputs from GAM. According to Figs. 3-5 we can identify two different climatic patterns and a transition in fire activity from NW region to HL and MED. Most of the fires ignite during summer, regardless of the region. Nonetheless, the proportion of winter wildfires is larger in NW than in any other region, with nearly $40 \%$ occurring during winter (Table 1 ). Summer number fires (Figs. 3-5) in NW appear to be associated with mid-range temperatures (T3-7) and mid-to-low precipitation (P6-2). NW winter fires are mainly related to relatively high temperatures (T7-8) and

Table 2

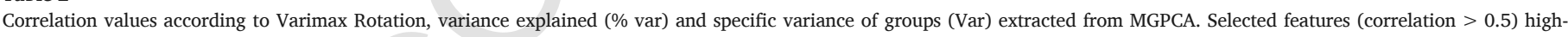
lighted in light grey.

\begin{tabular}{|c|c|c|c|c|c|c|c|c|c|c|c|c|c|c|c|c|c|c|}
\hline & \multicolumn{3}{|c|}{ NW S } & \multicolumn{3}{|c|}{ HL S } & \multicolumn{3}{|c|}{ MED S } & \multicolumn{3}{|c|}{ NW W } & \multicolumn{3}{|c|}{ HL W } & \multicolumn{3}{|c|}{ MED W } \\
\hline$\%$ var & 61.2 & 15.1 & 13.1 & 55.1 & 17.6 & 11.4 & 48.4 & 20.4 & 11.2 & 49.8 & 17.8 & 17.6 & 46.4 & 18.9 & 17.6 & 46.7 & 18.5 & 15.8 \\
\hline Var & 4.89 & 1.20 & 1.05 & 4.41 & 1.41 & 0.91 & 3.87 & 1.63 & 0.90 & 3.98 & 1.42 & 1.41 & 3.71 & 1.52 & 1.41 & 3.73 & 1.48 & 1.26 \\
\hline $\mathbf{N}$ & & -0.66 & & & -0.65 & & 0.50 & -0.14 & & 0.61 & -0.15 & & & -0.70 & & & -0.61 & \\
\hline B & 0.47 & & & 0.46 & & 0.14 & 0.44 & 0.18 & & 0.40 & 0.28 & & 0.48 & -0.14 & 0.11 & 0.46 & -0.18 & \\
\hline B500 & 0.50 & & & 0.53 & 0.15 & 0.16 & & 0.66 & & & 0.64 & & 0.52 & 0.19 & & 0.63 & 0.22 & \\
\hline NL & & -0.16 & 0.70 & & -0.21 & 0.67 & & & 0.88 & & -0.10 & 0.67 & -0.10 & -0.10 & 0.69 & & & 0.58 \\
\hline BL & & 0.14 & 0.75 & 0.10 & 0.16 & 0.72 & & & 0.38 & & & 0.69 & & 0.13 & 0.67 & & 0.18 & 0.88 \\
\hline NH & & -0.69 & & & -0.65 & & 0.51 & -0.15 & & 0.61 & -0.15 & & & -0.69 & & & -0.59 & \\
\hline
\end{tabular}




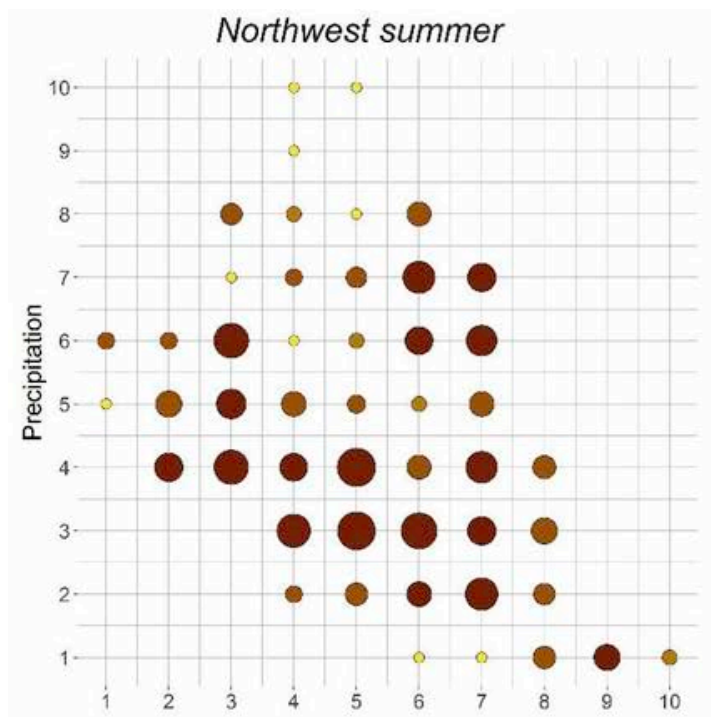

Hinterland summer

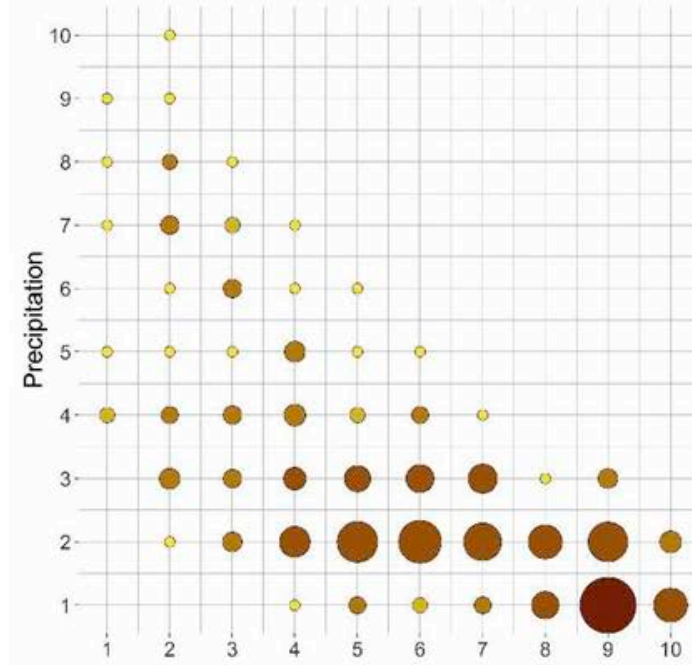

Mediterranean summer

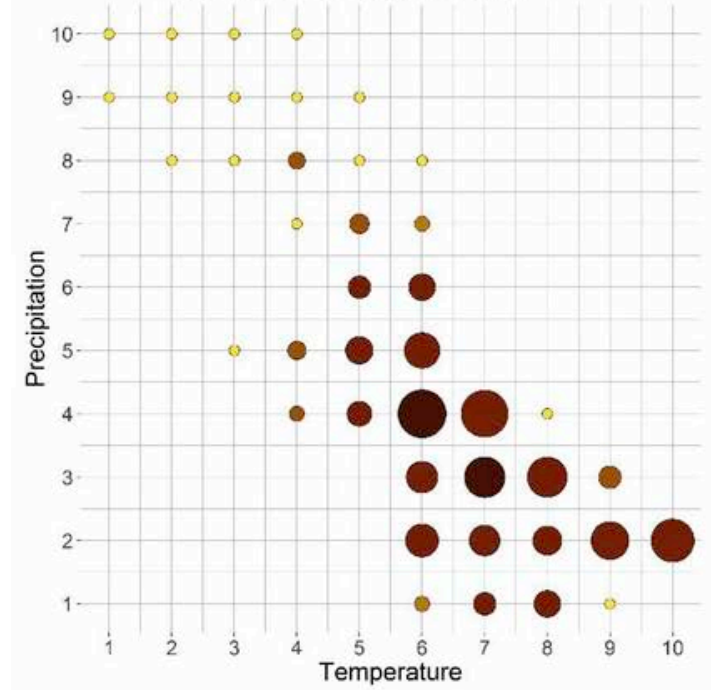

Northwest winter

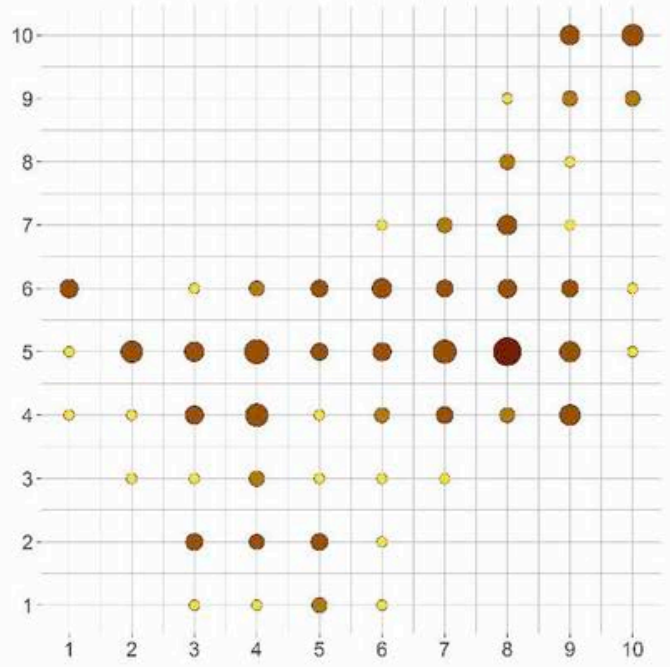

Hinterland winter

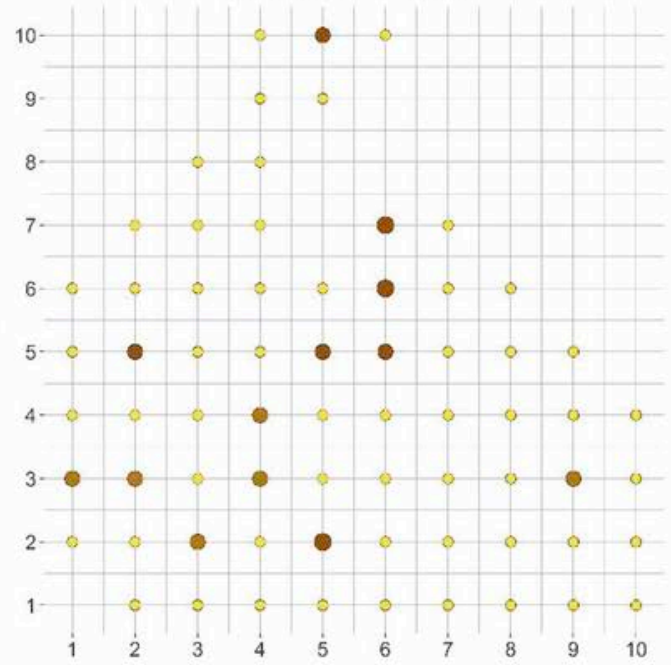

Mediterranean winter

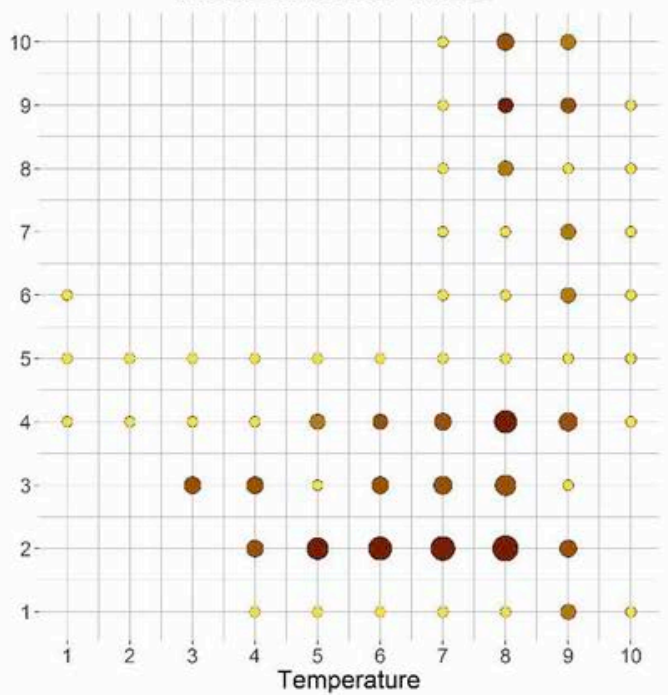

Burned area large fires (ha) $\square 10 \square 100 \square 1,000 \square 10,000 \square$ 100,000 $\square$ 1,000,000 Number of large fires $01 \bigcirc_{10} \bigcirc 50 \bigcirc 102$ 
Fig. 3. Multidimensional scatterplots for burned area from large fires. Note values are given on the logarithmic scale.

moderate rainfall (P5). GAM reports significant relationships for both climate variables, adding human pressure as significant predictor in all seasons. Partial plots revealed a positive association during summer of $\mathrm{N}$ with temperature and human pressure (i.e. the higher the temperature or human pressure the higher the number of fire events). In winter temperature shifts towards negative relationship whereas human pressure remains positive. Through HL to MED, $\mathrm{N}$ becomes closer to higher $\mathrm{T}$ and lower $\mathrm{P}$ in both seasons as climate conditions change from Oceanic to inner Mediterranean, finally reaching the Mediterranean climate domain on the coast. However, HL summer fires take place mainly in areas with very high temperatures (T9-10), whereas in MED, the temperature interval widens to 6-10. On the contrary, MED fires occur in areas with lower precipitation than fires in HL. This difference is also evidenced in GAM models which report non-significant relationship with $\mathrm{T}$ and significant in $\mathrm{P}$ in the Mediterranean region, and the opposite in HL (see Figs. A4 and A5). In turn, winter fires in HL are less selective, occurring under different conditions while MED shows fewer seasonal differences, and fires ignite under roughly the same conditions, i.e. high T (6-10) and low P (1-4) during winter or summer.

As with $\mathrm{N}, \mathrm{B} 500$ shows different behaviour across regions and seasons with NW as the most fire-prone region (Fig. 3). The pattern is, to some extent, similar to that of $\mathrm{N}$, as areas with a large occurrence of fire are more likely to retain most burned area, regardless of burned size. During summer, NW appears to be associated with relatively low P (3-4) and moderate intervals of T (P3-7), although relationships are found to be significant. However, during winter, most of the burned area from large fires is located in areas with high $\mathrm{T}(8)$ and moderate $\mathrm{P}$ (5), with P losing significance in GAM models. Note that B500 in winter is more strongly linked to high T than N (see Fig. A3). In HL and MED, B500 behaves mainly in the same way as $\mathrm{N}$, with the exception of summer wildfires in MED, where most of the area from large fires converges between P3-4 and T6-7, being more linked to P (significant $\mathrm{p}<0.05$ ) than $\mathrm{T}$ (non-significant).

Fig. 4 summarises the results from $\mathrm{BL}$ analysis. Again, the climatic pattern shows differences between NW and HL-MED. On the other hand, by putting BL and B500 together, we can establish some interesting associations. To a certain extent, there is a link between B500 and BL. In NW summer, the area from natural fires has its maximum values in several spots in P3-6 (significant $\mathrm{p}<0.05$ ) and T3-7 (non-significant). This pattern matches a part of B500 quite closely, suggesting that large summer fires under these conditions are mostly caused by natural ignitions. This association strengthens in HL and MED regions - again only during summer. GAM detects several significant relationships among $\mathrm{T}$ and $\mathrm{P}$ although no clear explanatory sense is observed in partial plots (Figs. A3-A5) other than P in NW winter.

Attending to the percent of deviance explained we found large differences among regions and seasons, in terms of the overall explained variance, and thus reliability. DE ranges from 0.42 to 0.41 in number of fires in NW regardless of the season to 0.13 in B500 in MED summer. Overall, winter DE values are higher than summer, especially in HL and MED. Lowest proportion of variance explained is usually obtained for natural fires.

Finally, an exploration of the relationship between $\mathrm{N}$ and HPI provides some remarkable insights. The link between $\mathrm{N}$ and human activity is noticeable. For instance, MGPCA (Table 2) reveals an association between $\mathrm{N}$ and $\mathrm{NH}$ in any given region or season; likewise GAM outputs report significant and positive relationships among $\mathrm{N}$ and HPI (Table 3 and Figs. A3-A5). According to the results in Fig. 5 and Fig A3, HPI mainly relates similarly to $\mathrm{N}$ in the NW region both during summer and winter. However, the relationship is slightly stronger in winter, although this association is less evident in HL and MED, espe- cially during winter (decreasing contribution, see Figs. A4 and A5), this fact is also supported by a lower deviance explained. In NW, summer fires ignited at low T (3-4) and moderate P (4-6) present high HPI average values. During winter, almost every combination of $\mathrm{P}$ and $\mathrm{T}$, taken from over 100 fires, have HPI average values around or higher than 0.2. Both in HL and MED summer, high HPI values are mostly located in T5-7 and P2-6.

\section{Discussion}

This paper characterizes and describes in detail fire regimes in mainland Spain, to identify their key features under the premise that different fire regimes exist across Spanish territory. We proposed a combination of statistical (MGPCA, VR and GAM) and visual techniques (MDS) as an approach to understanding climate-human-fire relationships, enabling the easy identification of contrasts in fire regime among the different regions analysed. This is particularly noticeable in the Northwest region, where fire behaviour is dissimilar to the rest of the study area in terms of both fire behaviour and ignition cause. In other words, fires are more frequent in Northwest, less related to climate conditions and more dependent on human pressure, whereas Hinterland-Mediterranean are more influenced by climate with greater seasonal differences.

Multi-group PCA combined with VR has led to identifying large fires (B500 and N500), overall fire frequency (N) and burned area of lightning fires (BL) as the features strongly relating to fire activity, and thus considered as key fire regime features. In addition, MGPCA also enables the importance of each fire feature to be explored. For instance, depending on the PC that a given feature is related to, we can determine its importance. In this regard, we have identified two different seasonal behaviours. Summer fire activity is more closely related to fire frequency (N located in PC1) and the impact of large fires appears on a secondary plane (B500 and N500 correlate more to PC2), whereas winter shows the opposite. In fact, in the case of the Northwest region the seasonal reversion of its components suggests that summer fire activity is mostly related to the impact of large fires, whereas winter fire behaviour is better explained by fire frequency from anthropogenic wildfires. In turn, the impact of natural fires, despite being systematically selected among the available features, always appears in PC3 both in terms of fire counts (NL) and affected area (BL). Varimax rotation results show that burned area coefficients are generally higher. Thus, natural fires appear to be better characterized in terms of affected area rather than number of fire events. Finally, MGPCA allows us to investigate the relationships among fire features. In this respect, the most relevant finding is that fire frequency $(\mathrm{N})$ is always associated with anthropogenic fires $(\mathrm{NH})$. On the one hand, this supports the hypothesis that Spanish fire regime is human-dominated (Rodrigues et al., 2014; San-Miguel-Ayanz et al., 2012).

The visual inspection of the MDS and the statistical interpretation of GAM models are particularly useful in terms of pyrogeography, i.e. the spatial distribution of fire regime features and their relationship with climate and socioeconomic factors (Fréjaville \& Curt, 2015). These procedures were applied to the selected key fire features. The analysis reveals that the NW fire regime, which is mostly dependent on human activities, is in contrast to Hinterland and Mediterranean. It is well known that in Northwest, fire is traditionally involved in several activities such as pasture burning and grazing (M. V. Moreno et al., 2014) close to forest areas. Conflicts between landowners or individuals and the forest administrations leading to arson are another particular characteristic of this area, where deliberate fires have increased since the early 90s (Leone et al., 2009). In any case, it is clear that hu- 


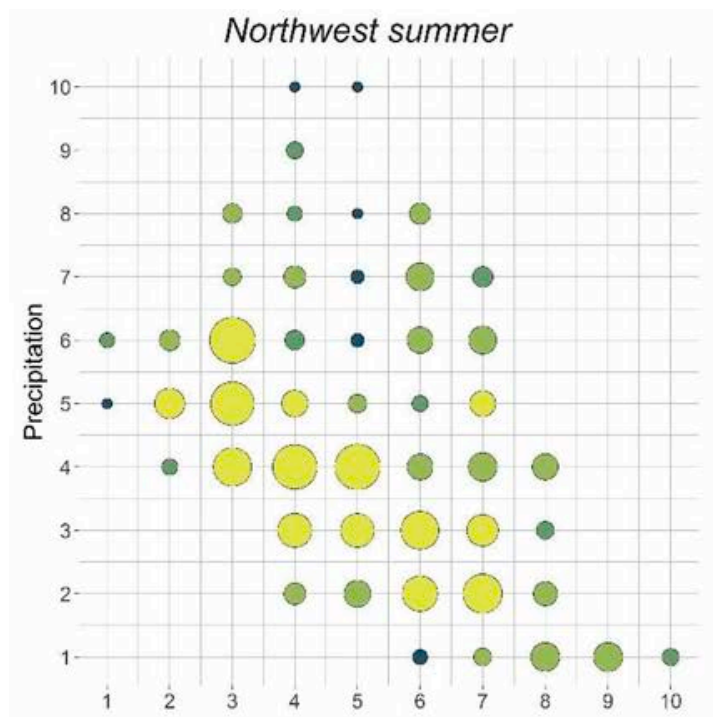

Hinterland summer

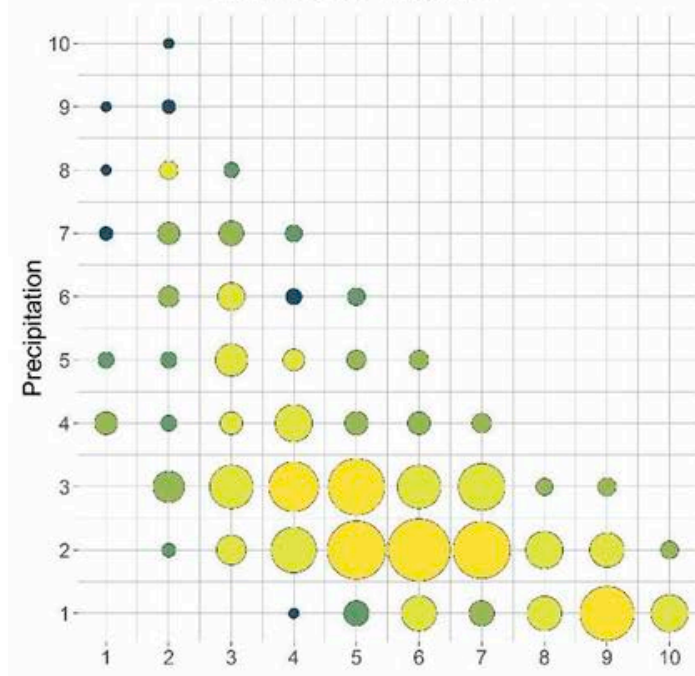

Mediterranean summer

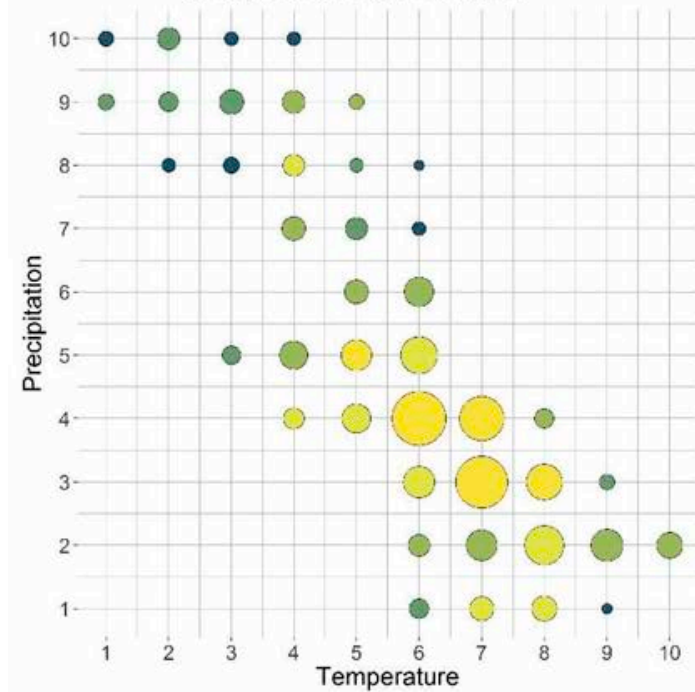

Burned area (ha) $\square 10 \square 100 \square 1,000 \square 10,000 \square 100,000$

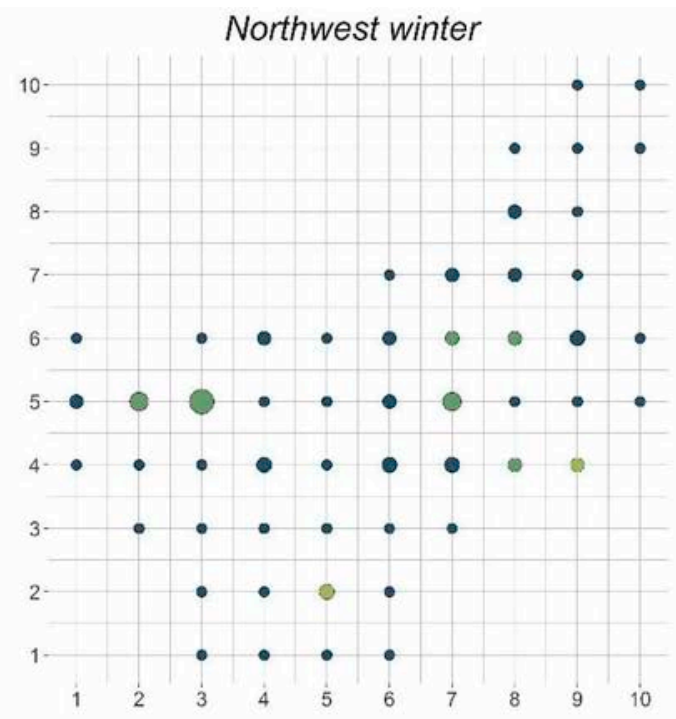

Hinterland winter

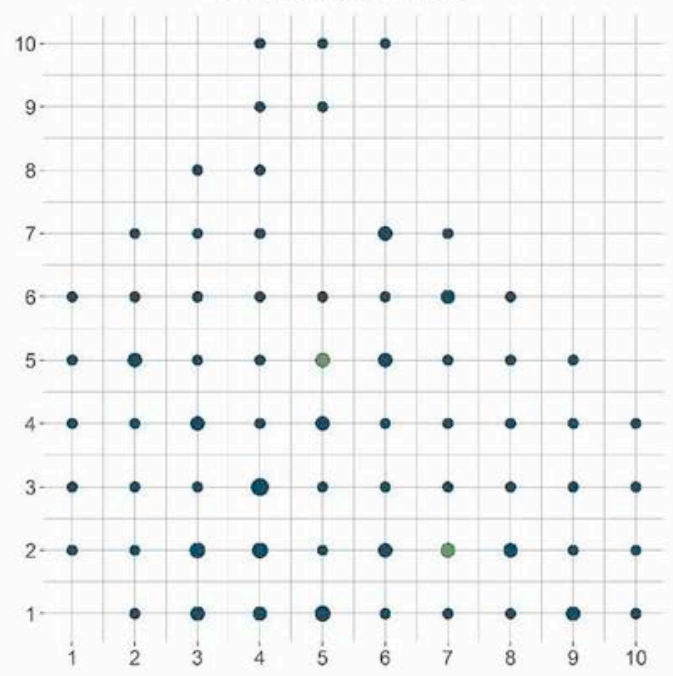

Mediterranean winter

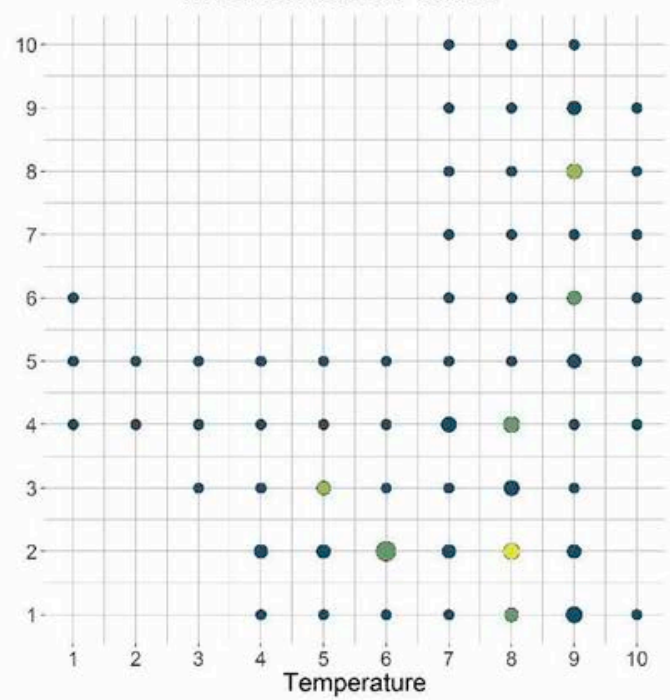

Number of natural fires $01010 \bigcirc 100 \bigcirc 200 \bigcirc 265$ 
Fig. 4. Multidimensional scatterplots for burned area from natural fires. Note values are given on the logarithmic scale.

man activity is responsible for, or at least has helped in shaping fire regime in the Northwest region. Moreover, winter fires are most frequent here than in any other region, not only in terms of number of fires, but proportion of overall fires. This fact makes the region particularly difficult in terms of wildfire modelling, since most of the variables used are usually concerned with summer fire activity (M. Rodrigues et al., 2014). On the other hand, wildfires are especially numerous during early spring coinciding with south winds (M. V. Moreno et al., 2014). In this case, there is an evident association between the hotter and drier conditions in this season, linked to this particular weather and, once again, to human factors - intentional fires peak (M. V. Moreno et al., 2014) - (Fig. A6 in Appendix 3 and Fig. 5).

Hinterland and Mediterranean regions share more similarities than differences. These regions show a stronger dependency on climate factors than Northwest. In fact, human pressure is generally associated with climate conditions unlikely to ignite fires, thus complementing the influence of climate. During summer, HL shows significant and positive relationships among N, B500 and temperature and negative with precipitation while MED displays significant relationships with precipitation alone. As expected, fire features adapt to the climate gradient. For instance, in these regions, natural fires play a more decisive role since they are more linked to burned area from large fires, so they have a greater impact in terms of affected area. Or what is the same, a high proportion of large fires in HL and MED regions have a natural source. Natural fires usually hinder suppression tasks, since accessibility to the burning area may be significantly difficult. Thus natural fire has a higher chance of propagating than human-caused fires since climate and fuel conditions are usually favourable (Chuvieco, 2009a, 2009b). Therefore, we can safely assume that natural fires explain, or at least have some involvement with, a part of the burned area from large fires. HL, which can be considered as a transition area between pure Eurosiberian conditions to Mediterranean ones, is still influenced by human activities, although human factors are somewhat complementary to climate conditions. Multi-group PCA supports this to some extent. PC1 meets large fire activity with burned area from human-caused fires, suggesting that winter wildfires may have a human origin. The reasons explaining this fact may be found in agricultural practices or in negligence and accidents from recreational use of forest areas (Leone et al., 2003). With regard to the MED region, the situation is slightly different compared to HL. Fire frequency and total affected are more influenced by climate, specifically by precipitation or better the lack of it. The more important role of precipitation and the lesser human influence is manifested in the huge area of large fires, greater than any other region (Table 1), favoured by dry fuels, something that several authors have previously pointed out (Pausas \& Fernández-Muñoz, 2012; Pausas, 2004; Vázquez, Climent, Casais, \& Quintana, 2015).

In summary (Table 4), we can state that fire regime is strongly influenced by human activities in each region and season. Wildfire frequency is always significantly related to temperature, precipitation and human pressure, except in the case on MED during summer which is only tied to $\mathrm{P}$ and HPI. Large fires exhibit a strong relationship with precipitation during summer, being also linked to high temperature in HL. Natural fires are somewhat tied to large fires although better explained by precipitation. Finally, from a seasonal standpoint, winter is perhaps the most complex season of the year, due to climate conditions losing part of their influence and human activities taking over, especially evident in the case of the NW and HL regions.

Nevertheless, our research has several limitations that must be pointed out. Firstly, our analysis is focused on a single study period (1974-2010), and even though it includes the seasonal scale, does not include temporal evolution of fire features, and fire activity has most likely changed over the temporal span (see Moreno et al., 2014). On the other hand, the scope is focused on several features extracted and constructed on the basis of the available fire information. However, other fire metrics beyond fire reports (e.g. fire severity or intensity) may be included in further analysis.

\section{Conclusions and further research}

In this paper, we have described and characterized the major characteristics of the fire regimes in Spanish mainland through quantitative and visual analyses of relationships between fire components, climate and human pressure, using fire data from 1974 to 2010. We were able to determine the most important fire regime features and analyse fire regime on that basis. Our results suggest that not all the regions examined have the same fire regime, although they share some characteristics, as in the case of HL and MED during summer.

The combination of multi-group PCA techniques with visual analysis of multidimensional scatterplots and GAM regression has proved to be a powerful toolset that enables characterization and investigation of fire regimes. On the one hand, MGPCA has revealed that the main features of Spanish fire regimes are total frequency of fires, burned area from fires over 500 ha big and burned area of natural fires. In addition, the analysis of these fire regime features in the context of climate and human factors enabled the main drivers behind fire regime characteristics over regions and seasons to be established. In this sense, the NW region represents a paradigmatic example of the impact from human factors, especially during winter, whereas Hinterland and Mediterranean regions are mostly dependent on climate conditions.

Overall, the NW region is characterized by fire frequency and large fire activity during summer, whereas during winter, anthropogenic fires play a more important role. HL reproduces the same behaviour, human fires during winter and large fires during summer. Finally, MED is characterized by burned area metrics, whereas fire frequency is located in first place during summer but remains in second place, during winter. In any case, fire activity shows contrasting characteristics among regions and seasons. Therefore, fire modelling should take this seasonality into account in order to produce more reliable results.

The identification of key features opens new research lines that shall be further investigated. For instance, the spatial and temporal variability of fire regimes must be explored in depth. This means that, rather than consider homogeneous regions (e.g. NW, HL and MED), we must outline them on the basis of fire features. On the other hand, deeper insights into the temporal evolution of fire regimes have to be provided, since fire activity has most likely changed over the years, the same as climate and human factors on which they are dependent.

\section{Acknowledgements $\Omega$}

This work has been financed by the Spanish Ministry of Education: FPU grant 13/06618. We would like to thank Professor J.C. González-Hidalgo and his research group for providing climate data. In addition, we are very grateful to the reviewers for their valuable comments, which have improved the final manuscript.

\section{Appendix A. Supplementary data}

Supplementary data related to this article can be found at https:// doi.org/10.1016/j.apgeog.2017.10.007. 
Northwest summer

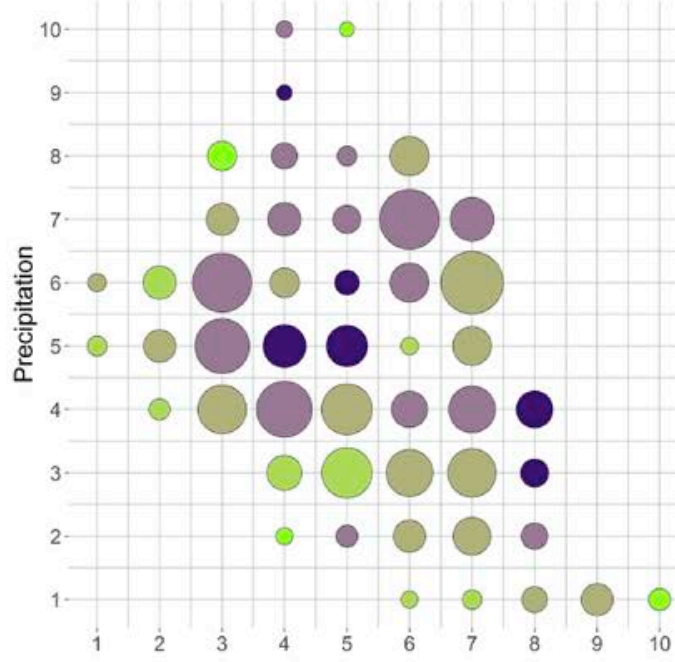

Hinterland summer

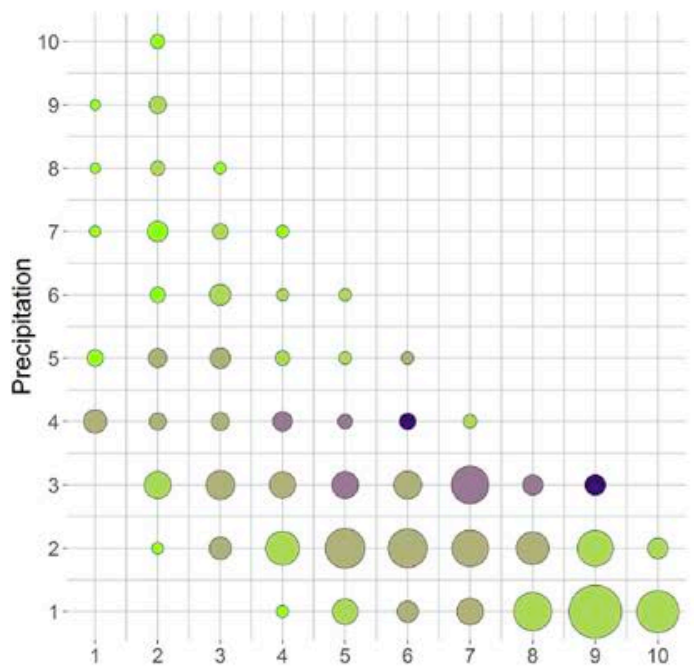

Mediterranean summer

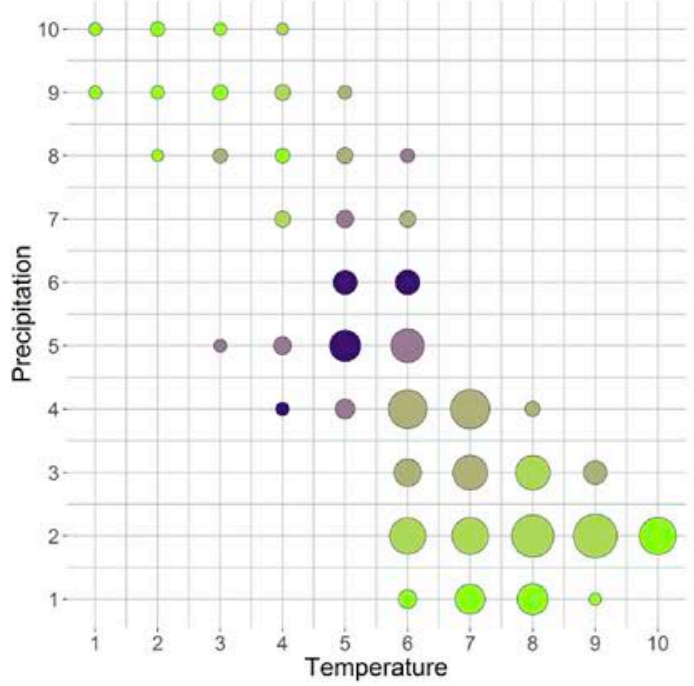

Human Pressure $\square 0.10 \square 0.15 \square 0.20 \square 0.25 \square 0.35$
Northwest winter

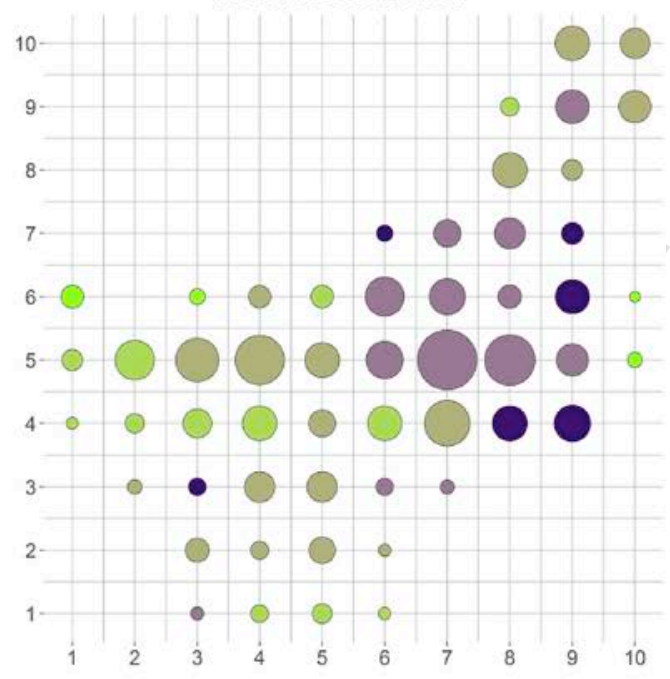

Hinterland winter

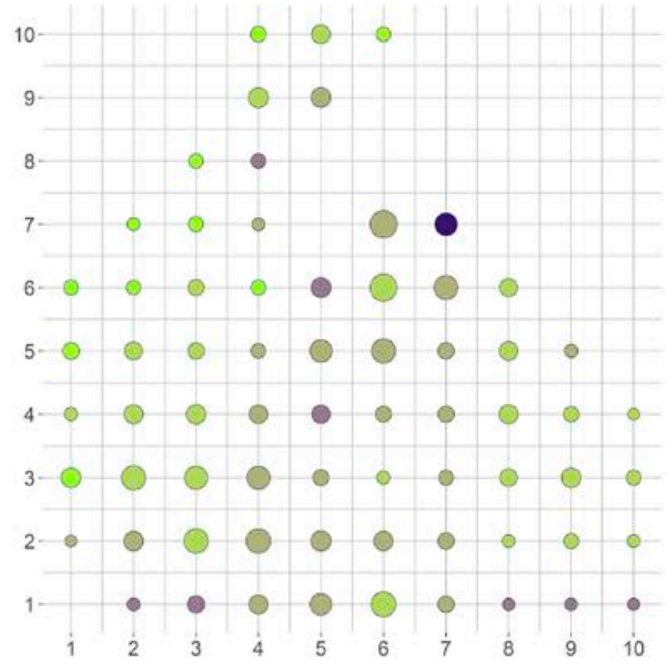

Mediterranean winter

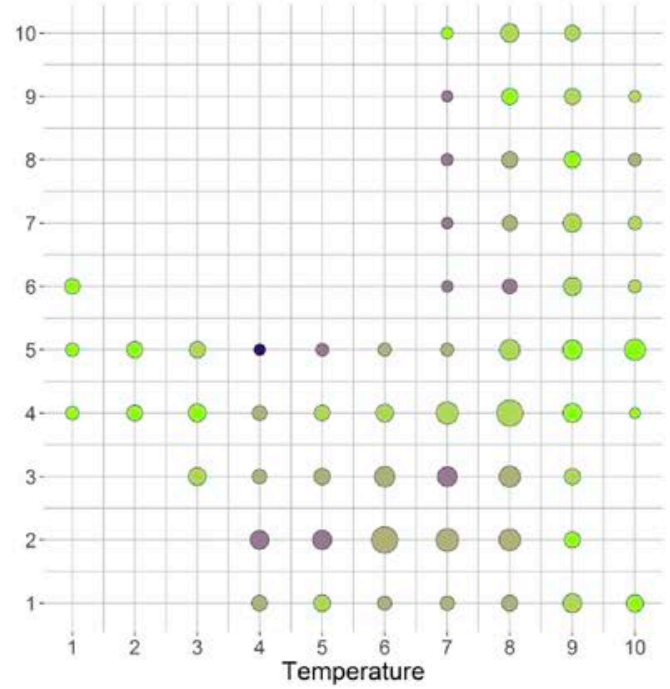

Number of fires $010100100 \bigcirc 1,000 \bigcirc 7,636$ 
Fig. 5. Multidimensional scatterplots for HPI. Note values are given on the logarithmic scale.

Table 3

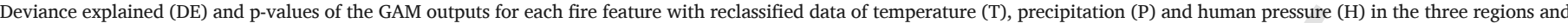

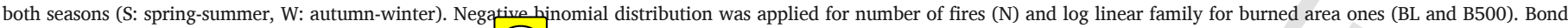
values are significant $(<0.05)$

\begin{tabular}{|c|c|c|c|c|c|c|c|c|c|c|c|c|}
\hline & $D E$ & NW S & & & $D E$ & HL S & & & $D E$ & MED S & & \\
\hline & & $\mathrm{T}$ & $\mathrm{P}$ & $\mathrm{H}$ & & $\mathrm{T}$ & $\mathrm{P}$ & $\mathrm{H}$ & & $\mathrm{T}$ & $\mathrm{P}$ & $\mathrm{H}$ \\
\hline $\mathrm{N}$ & 0.41 & 0.000 & 0.000 & 0.000 & 0.14 & 0.000 & 0.000 & 0.000 & 0.2 & 0.074 & 0.000 & 0.000 \\
\hline BL & 0.18 & 0.644 & 0.000 & - & 0.10 & 0.035 & 0.104 & - & 0.2 & 0.492 & 0.039 & - \\
\hline \multirow[t]{3}{*}{ B500 } & 0.17 & 0.012 & 0.000 & - & 0.12 & 0.000 & 0.000 & - & 0.13 & 0.245 & 0.000 & - \\
\hline & $D E$ & NW W & & & $D E$ & HL W & & & $D E$ & MED W & & \\
\hline & & $\mathrm{T}$ & $\mathrm{P}$ & $\mathrm{H}$ & & $\mathrm{T}$ & $P$ & $\mathrm{H}$ & & $\mathrm{T}$ & $P$ & $\mathrm{H}$ \\
\hline $\mathrm{N}$ & 0.42 & 0.000 & 0.000 & 0.000 & 0.32 & 0.000 & 0.000 & 0.000 & 0.21 & 0.000 & 0.000 & 0.000 \\
\hline BL & 0.2 & 0.062 & 0.000 & - & 0.2 & 0.000 & 0.000 & - & 0.31 & 0.000 & 0.000 & - \\
\hline B500 & 0.15 & 0.013 & 0.093 & - & 0.3 & 0.2 & 0.000 & - & 0.25 & 0.034 & 0.000 & - \\
\hline
\end{tabular}

Table 4

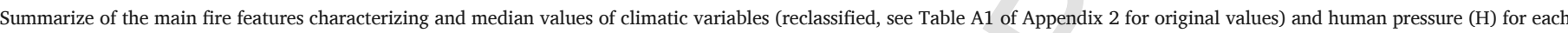

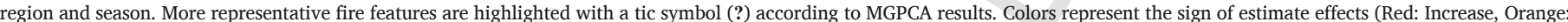

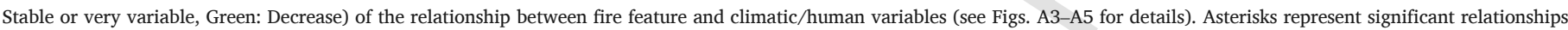
between fire features and climate/human variables.

\begin{tabular}{|c|c|c|c|c|c|c|c|c|c|c|c|c|c|c|c|c|c|c|c|c|c|c|c|c|}
\hline & \multicolumn{4}{|c|}{ NW S } & \multicolumn{4}{|c|}{ HL S } & \multicolumn{4}{|c|}{ MED S } & \multicolumn{4}{|c|}{ NW W } & \multicolumn{4}{|c|}{ HL W } & \multicolumn{4}{|c|}{ MED W } \\
\hline & & $\mathrm{T}$ & $\mathrm{P}$ & $\mathrm{H}$ & & $\mathrm{T}$ & $P$ & $\mathrm{H}$ & & $\mathrm{T}$ & $\mathrm{P}$ & $\mathrm{H}$ & & $\mathrm{T}$ & $P$ & $\mathrm{H}$ & & $\mathrm{T}$ & $\mathrm{P}$ & $\mathrm{H}$ & & $\mathrm{T}$ & $P$ & $\mathrm{H}$ \\
\hline & & 5 & 4 & 0.2 & & 6 & 2 & 0.1 & & 7 & 2 & 0.1 & & 6 & 5 & 0.2 & & 5 & 2 & 0.1 & & 8 & 4 & 0.1 \\
\hline BL & J & 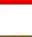 & * & & J & * & & & & & * & & $J$ & & $*$ & & J & $*$ & $*$ & & $J$ & $*$ & $*$ & \\
\hline B500 & J & $*$ & * & & J & $*$ & * & & $J$ & & * & & $J$ & * & & & J & & $*$ & & $J$ & $*$ & $*$ & \\
\hline
\end{tabular}

\section{References}

Archibald, S., Lehmann, C.E.R., Gómez-Dans, J.L., Bradstock, R.A., 2013. Defining pyromes and global syndromes of fire regimes. Proceedings of the National Academy of Sciences 110 (16), 6442-6447. https://doi.org/10.1073/pnas.1211466110.

Boadi, C., Harvey, S.K., Gyeke-dako, A., 2015. Modelling of fire count data: Fire disaster risk in Ghana. SpringerPlus 4 (794)https://doi.org/10.1186/s40064-015-1585-3.

Calvo, J.L., Pueyo, A., 2008. Atlas Nacional de España: Demografía. Geográfica 104, 393-396.

Chuvieco, E., 2009a. In: Chuvieco, E. (Ed.), Earth observation of wildland fires in mediterranean ecosystems. Springer Verlag Geosciences, Berlin, Heidelberg.

Chuvieco, E., 2009b. Global impacts of fire. In: Chuvieco, E. (Ed.), Earth observation of wildland fires in mediterranean ecosystems. Springer Berlin Heidelberg, New York, pp. 1-10. https://doi.org/10.1007/978-3-642-01754-4.

Chuvieco, E., Giglio, L., Justice, C., 2008. Global characterization of fire activity: Toward defining fire regimes from earth observation data. Global Change Biology 14 (7), 1488-1502. https://doi.org/10.1111/j.1365-2486.2008.01585.x.

Craven, P., Wahba, G., 1978. Smoothing noisy data with spline functions. Numerische Mathematik 31 (4), 377-403. https://doi.org/10.1007/BF01404567.

Darques, R., 2016. Wildfires at a Pan-Mediterranean scale: Human-environment dynamics through MODIS data. Human Ecology 2009, https://doi.org/10.1007/ s10745-015-9802-9.

Drobyshev, I., Niklasson, M., Linderholm, H.W., 2012. Forest fire activity in Sweden: Climatic controls and geographical patterns in 20th century. Agricultural and Forest Meteorology 154-155, https://doi.org/10.1016/j.agrformet.2011.11.002, (April 2016).

Eslami, A., Qannari, E.M., Kohler, A., Bougeard, S., 2013a. Analyses factorielles de données structurées en groupes d'individus. Journal de La Société Française de Statistique 154 (3), 44-57, Retrieved from http://journal-sfds.fr/index.php/J-SFdS/article/ view/208/193.

Eslami, A., Qannari, E.M., Kohler, A., Bougeard, S., 2013b. General overview of methods of analysis of multi-group datasets. Revue Des Nouvelles Technologies de l'Information $25,108-123$.

Flury, B.N., 1984. Common principal components in K groups. Journal of the American Statistical Association 79 (388), 892-898, Retrieved from http://www.jstor.org/ stable/2288721.

Francos, M., Pereira, P., Alcañiz, M., Mataix-Solera, J., Úbeda, X., 2016. Impact of an intense rainfall event on soil properties following a wildfire in a Mediterranean environment (North-East Spain). Science of the Total Environment https://doi.org/10.1016/ j.scitotenv.2016.01.145, (in press).
Fréjaville, T., Curt, T., 2015. Spatiotemporal patterns of changes in fire regime and climate: Defining the pyroclimates of south-eastern France (Mediterranean Basin). Climatic Change 129 (1-2), 239-251. https://doi.org/10.1007/s10584-015-1332-3.

Ganteaume, A., Camia, A., Jappiot, M., San-Miguel-Ayanz, J., Long-Fournel, M., Lampin, C., 2013. A review of the main driving factors of forest fire ignition over Europe. Environmental Management 51 (3), 651-662. https://doi.org/10.1007/ s00267-012-9961-z.

Golub, G.H., Heath, M., Wahba, G., 1979. Generalized cross-validation as a method for choosing a good ridge parameter. Technometrics 21 (2), 215-223, Retrieved from http://www.stat.wisc.edu/ wahba/ftp1/oldie/golub.heath.wahba.pdf.

González-Hidalgo, J.C., Brunetti, M., de Luis, M., 2011. A new tool for monthly precipitation analysis in Spain: MOPREDAS database (monthly precipitation trends December 1945-November 2005). International Journal of Climatology 31 (5), 715-731. https: //doi.org/10.1002/joc.2115.

González-Hidalgo, J.C., Peña-Angulo, D., Brunetti, M., Cortesi, N., 2015. MOTEDAS: A new monthly temperature database for mainland Spain and the trend in temperature (1951-2010). International Journal of Climatology 35 (15), 4444-4463. https://doi. org/10.1002/joc. 4298 .

Hastie, T., Tibshirani, R., 1986. Generalized additive models. Statistical Science 1 (3), 297-318, Retrieved from https://projecteuclid.org/download/pdf_1/euclid.ss/ 1177013604.

Hernandez, C., Keribin, C., Drobinski, P., Turquety, S., 2015. Statistical modelling of wildfire size and intensity: A step toward meteorological forecasting of summer extreme fire risk. Annals of Geophysics 33, 1495-1506. https://doi.org/10.5194/ angeo-33-1495-2015.

Horst, P., 1965. Factor analysis of data matrices, 1st ed. Holt, Rinehart and Winston, New York, https://doi.org/10.2307/1421153.

Jones, K., Almond, S., 1992. Moving out of the linear rut: The possibilities of generalized additive models. Transactions of the Institute of British Geographers 17 (4), 434-447. https://doi.org/10.2307/622709.

Kaiser, H.F., 1958. The varimax criterion for analytic rotation in factor analysis. Psychometrika 23 (3), 187-200. https://doi.org/10.1007/BF02289233.

Kaiser, H.F., 1960. The application of electronic computers to factor analysis. Educational and Psychological Measurement 20, 141-151.

Krawchuk, M.A., Moritz, M.A., Parisien, M.A., Van Dorn, J., Hayhoe, K., 2009. Global pyrogeography: The current and future distribution of wildfire. PLoS ONE 4 (4)https:// doi.org/10.1371/journal.pone.0005102.

Krebs, P., Pezzatti, G.B., Mazzoleni, S., Talbot, L.M., Conedera, M., 2010. Fire regime: History and definition of a key concept in disturbance ecology. Theory in Biosciences 129, 53-69. https://doi.org/10.1007/s12064-010-0082-z.

Krzanowski, W.J., 1984. Principal component analysis in the presence of group structure. Journal of the Royal Statistical Society Series C (Applied Statistics) 33 (2), 164-168. 
Le Page, Y., Oom, D., Silva, J.M.N., Jönsson, P., Pereira, J.M.C., 2010. Seasonality of vegetation fires as modified by human action: Observing the deviation from eco-climatic fire regimes. Global Ecology and Biogeography 19 (4), 575-588. https://doi.org/10. 1111/j.1466-8238.2010.00525.x.

Leone, V., Koutsias, N., Martínez, J., Vega-García, C., Allgöwer, B., Lovreglio, R., 2003. The human factor in fire danger assessment. In: Chuvieco, E. (Ed.), Wildland fire danger estimation and mapping. The role of remote sensing data. World Scientific Publishing, Singapore.

Leone, V., Lovreglio, R., Martín, M.P., Martínez, J., Vilar, L, 2009. Human factors of fire occurrence in the mediterranean. In: Chuvieco, E. (Ed.), Earth observation of wildland fires in mediterranean ecosystems. Springer Berlin Heidelberg, New York, pp. 149-170. https://doi.org/10.1007/978-3-642-01754-4_11.

Marcoux, H.M., Daniels, L.D., Gergel, S.E., Da Silva, E., Gedalof, Z., Hessburg, P.F., 2015. Differentiating mixed- and high-severity fire regimes in mixed-conifer forests of the Canadian Cordillera. Forest Ecology and Management 341, 45-58. https://doi.org/10. 1016/j.foreco.2014.12.027

Mardia, K.V., Kent, J.T., Bibby, J.M., 1979. Multivariate analysis. Academic Press, London.

Martínez, J., Chuvieco, E., Martín, M.P., 2004. Estimating human risk factors in wildland fires in Spain using logistic regression. In: II international symposium on fire economics, planning and policy: A global vision, Cordoba.

Moreno, M.V., Conedera, M., Chuvieco, E., Pezzatti, G.B., 2014. Fire regime changes and major driving forces in Spain from 1968 to 2010. Environmental Science and Policy 37, 11-22. https://doi.org/10.1016/j.envsci.2013.08.005.

Moreno, M.V., Malamud, B.D., Chuvieco, E., 2011. Wildfire frequency-area statistics in Spain. Procedia Environmental Sciences 7, 182-187. https://doi.org/10.1016/j. proenv.2011.07.032

Murphy, B.P., Williamson, G.J., Bowman, D.M.J.S., 2011. Fire regimes: Moving from a fuzzy concept to geographic entity. New Phytologist 192 (2), 316-318. https://doi. org/10.1111/j.1469-8137.2011.03893.x.

Pausas, J.G., 2004. Changes in fire and climate in the eastern iberian peninsula (Mediterranean Basin). Climate Change 63, 337-350.

Pausas, J.G., Fernández-Muñoz, S., 2012. Fire regime changes in the Western Mediterranean Basin: From fuel-limited to drought-driven fire regime. Climatic Change 110, 215-226. https://doi.org/10.1007/s10584-011-0060-6.

Pechony, O., Shindell, D.T., 2010. Driving forces of global wildfires over the past millennium and the forthcoming century. Proceedings of the National Academy of Sciences of the United States of America 107 (45), 19167-19170. https://doi.org/10.1073/ pnas. 1003669107.

Pyne, S.J., Andrews, P.L., Laven, R.D., 1996. Introduction to wildland fire, 2o Edition.
Quazi, S.A., Ticktin, T., 2016. Understanding drivers of forest diversity and structure in managed landscapes: Secondary forests, plantations, and agroforests in Bangladesh. Forest Ecology and Management 366, 118-134. https://doi.org/10.1016/j.foreco. 2016.01.024.

R Core Team, 2016. R: A language and environment for statistical computing. R Foundation for Statistical Computing, Vienna.

Rodrigues, M., de la Riva, J., Fotheringham, S., 2014. Modeling the spatial variation of the explanatory factors of human-caused wildfires in Spain using geographically weighted logistic regression. Applied Geography 48, 52-63. https://doi.org/10.1016/j.apgeog. 2014.01.011.

Rodrigues, M., Jiménez, A., de la Riva, J., 2016. Analysis of recent spatial-temporal evolution of human driving factors of wildfires in Spain. Natural Hazards 84 (3), 2049-2070. https://doi.org/10.1007/s11069-016-2533-4.

San-Miguel-Ayanz, J., Moreno, J.M., Camia, A., 2013. Analysis of large fires in European Mediterranean landscapes: Lessons learned and perspectives. Forest Ecology and Man agement 294, 11-22. https://doi.org/10.1016/j.foreco.2012.10.050.

San-Miguel-Ayanz, J., Schulte, E., Schmuck, G., Camia, A., Strobl, P., Liberta, G., ... Amatulli, G., 2012. Comprehensive monitoring of wildfires in europe: The european forest fire information System (EFFIS). In: Tiefenbacher, J. (Ed.), Approaches to managing disaster - assessing hazards, emergencies and disaster impacts. pp. 87-105.

Syphard, A., Radeloff, V., Keeley, J., Hawbaker, T., Clayton, M., Stewart, S., et al., 2007. Human influences on California fire regimes. Ecological Applications 17 (5), 1388-1402. https://doi.org/10.1890/06-1128.1.

Vázquez, A., Climent, J.M., Casais, L., Quintana, J.R., 2015. Current and future estimates for the fire frequency and the fire rotation period in the main woodland types of peninsular Spain: A case-study approach. Forest Systems 24 (2), 13. https://doi.org/ $10.5424 / \mathrm{fs} / 2015242-06454$

Vélez, R., 2001. Fire situation in Spain. In: Goldammer, J.G., Mutch, R.W., Pugliese, P. (Eds.), Global forest fire assessment 1990-2000. FAO, Roma, pp. 295-301.

Wang, Y., Anderson, K.R., 2010. An evaluation of spatial and temporal patterns of lightning- and human-caused forest fires in Alberta, Canada, 1980-2007. International Journal of Wildland Fire 19 (8), 1059-1072. https://doi.org/10.1071/WF09085.

Whitman, E., Batllori, E., Parisien, M.-A., Miller, C., Coop, J.D., Krawchuk, M.A., ... Haire, S.L., 2015. The climate space of fire regimes in north-western North America. Journal of Biogeography 42 (9), 1736-1749. https://doi.org/10.1111/jbi.12533.

Xu, D., Shao, G., Dai, L., Hao, Z., Tang, L., Wang, H., 2006. Mapping forest fire risk zones with spatial data and principal component analysis. Science in China, Series E: Technological Sciences 49 (Suppl. 1), 140-149. https://doi.org/10.1007/ s11434-006-8115- 